\title{
Collaborative Online International Learning Experience in Practice Opportunities and Challenges
}

\author{
Marilú Marcillo-Gómez ${ }^{1 *}$,Bendreff Desilus ${ }^{2}$
}

\begin{abstract}
Academic institutions of higher education, and especially Jesuit institutions, face the challenge of educating students who often face unique financial challenges. These challenges can have an impact on access to quality education and experience. Given our globalized environment, among these challenges is the opportunity for students to participate in a study-abroad experience while at the university. Today, through the use of technology it is possible for institutions of higher education to offer these collaborative learning experiences to those students who may not be able to travel. This paper will detail a pedagogical approach which emphasizes using collaborative online international engagement.
\end{abstract}

Keywords: study-abroad; online collaboration; international collaboration; cross-cultural learning; Hofstede; blended learning

Background: Institutions of higher learning today are faced with the challenge of providing unique academic opportunities for learning that in many cases makes use of technology either as a fully online or blended curriculum. However, it's not simply offering online/blended courses that matter, but what you do with those technologies that makes the difference for students today. "As forms of online postsecondary study become "normal," the prospective student may begin to ask, "What does online delivery enable this particular institution to do, relative to other institutions?" Just as prospective students are interested in the quality of an institution's library collection, or the services afforded by electricity (and not the basic facts that an institution has books or electricity), so "online" increasingly may become commoditized, and it will be what institutions "do" with online delivery that will count" (Allen, Garrett \& Seaman, 2007, p. 19). Millennials perception of about the classroom has changed and they want the flexibility to be able to engage in learning from their IPads, Smartphones, computers in an airport, or while on vacation at the beach; virtually anywhere (Folkers, 2005). These technological changes coupled by global external forces encouraging companies to offshore labor from virtually anywhere means that the role universities play in preparing students for this complex work environment needs to factor in these changes. One way to do this, utilizes what most institutions have; an LMS, access to the internet, textbooks, network of affiliated universities, and students receptive to increasing their global scope of knowledge. These coupled together means that is possible to offer a collaborative online learning opportunity which enables students to gain that study-abroad experience without leaving home.

$21^{\text {st }}$ International Association of Jesuit Business Schools (IAJBS)

$18^{\text {th }}$ Colleagues in Jesuit Business Education (CJBE)

\section{Introduction}

The purpose of this paper is to share insight about the collaborative teaching experience between two faculties; one in the United States and one in Mexico City. It will offer a recap of what we have learned through this experience and what we would do similarly and what we would do differently given the opportunity to collaborate in the future. The paper will highlight how this pedagogy can provide students with a unique academic opportunity, the pre-session preparation and training undergone to enable the course to take place, the challenges of teaching students in two countries, how culture affected perception and participation and recommendations for incorporating this pedagogy within any curriculum and university as well as the importance of common Learning Module System (LMS) and other technologies to ensure adequate communication between colleagues. The paper is broken into the sections of Methodology, Pre-Course Preparation, Course Pedagogy, Challenges Related to Culture, Challenges Related to Learning Module System (LMS), Institutional Support, Opportunities, Recommendations for future Collaborative Online Instruction and Conclusion.
Our initial collaboration began as a direct result of the U.S faculty's participation with the State University of New York (SUNY) program of Collaborative Online International Learning program (COIL). While this was a precursor to this collaboration, the role that SUNY COIL contributed was to help to facilitate the initial process of dialogue between the schools. It was the U.S. faculty, however, who sought a partner school from her network of acquaintances. Therefore it is important to note that other academic institutions within a network of schools can easily find a partner faculty in similar disciplines and incorporate this pedagogy. There was no unique technology incorporated in this collaboration that is different from what most institutions currently have access to: an LMS, the Internet and any virtual channel of communication, like Skype and email. Additionally we used a textbook and recorded lectures which were posted to the LMS website.

\section{Methodology}

The primary research included observational research with local students in an International Business course at two universities.

(1) Saint Peter's University, Jersey City New Jersey, USA.

(2) Universidad La Salle, MX.

* Corresponding author: mmarcillogomez@saintpeters.edu 
Secondly, students provided first-hand accounts of their experience in the course. Both of these coupled together provided the researchers a better understanding of student perception and experience. The researchers, as instructors of this course, maintained a journal of their experience during the pre-session training which provides insight about the challenges and preparation required to teach a collaborative online course. Since many Catholic institutions serve a diverse population of students, many of whom are part of the under-represented classes with limited financial resources which inhibit opportunities to study-abroad, it is important to find new pedagogies which help to equalize this learning experience. Our pedagogical approach incorporates technology and offers students the unique opportunity to engage with others outside of their local communities. Through this process of engagement we enable those students who may not be able to afford to participate in travel abroad experiences to participate, learn and build communities with others who are both similar and different from themselves.

\section{Pre-Course Preparation}

Part of the course preparation required us to maintain a weekly journal of our progress. Our course preparation took about eight weeks where we participated in weekly discussions via Google Docs, and Skype about topics related to course expectations, pedagogy and technology. We selected a topic for the course which would be imbedded into an existing International Business course. We then selected books. Afterward we reviewed and selected a specific book we selected chapters we felt we should cover within the six weeks this course took place. The recommended length should be at minimum four weeks in order for students to get to know one another. We created a syllabus with course expectations. Both institutions were using Moodle for their LMS and we made the decision that the instruction would be in English given the Mexican's students familiarity with English and the American students' lack of familiarity with Spanish. Finally we selected La Salle's Moodle system as the lead LMS to facilitate a sense of community and supplement it with Skype for face to face team discussions. We worked extensively with the Moodle coordinator at La Salle to create student usernames, passwords, and prepared the course assignments and videos. The U.S. faculty had the opportunity to travel to Mexico for a week to meet with the students, partner faculty, Moodle coordinator, and the School of Business leadership; however this could also be accomplished virtually.

\section{Course Pedagogy}

The course title was Communicating between Cultures and was based on the textbook by the same title written by Samovar, McDaniel, Roy (2013), the topics addressed in this course were:

- Topic 1: Intercultural Communication: Interaction in a Multicultural World

Discussion Topic: During this first week each student was asked to introduce themselves to the class including their background, where they were born, religious affiliation if any, common customs, traditions, dances or foods that are customary in their culture, size of family, Proximity to extended family or how close (distance) is their extended family and what impact do they have on the student?

Given the topic of this course this section reflected on the role that culture plays in the lives of everyone in society and also, how that role can produce different results in the interaction of people in a globalized world. Within this topic we analyzed the following subtopics:

- Intercultural communication

- Reactions to culture shock

- Respect cultural differences

The first week it is extremely important for students and faculty to participate actively in sharing as much personal information as possible in order to facilitate class familiarity.

- Topic 2: The Deep Structure of Culture: Lessons from the family

Discussion Topic: Working individually (first part of week Sunday through Tuesday); the American student will list the American cultural values and the Mexican partner will list the Mexican Cultural Values, using examples found in advertising campaigns that illustrate those values. For example, the advertising slogan, "Just Do it," from an athletic-shoe manufacturer, reflects the American values of perseverance and accomplishment. Students will then work collaboratively in the later part of the week (Wednesday through Saturday) to go over their findings.

Within the discussion forum students are asked to "examine the concept of high and low-context cultures. What problems can you anticipate when you are communicating with someone who holds a different context orientation?"

The aim of this topic was to understand how and why people have different perceptions about the culture. We also put emphasis on the role of the family in cultural conception of individual members and the importance of a culture's deep structure to any study of intercultural communication.

The subtopics were:

- The deep structure of culture

- The importance of family

- Globalization and families

- Cultural variants in family interaction, etc.

In this second week of the course it is important to get students actively interacting about a selected topic (where opinions and perceptions will vary as this will begin to help students understand key differences and similarities). Additionally, by the end of this week, students were paired with a partner from the collaborating institution and were asked to contact each other via Skype so that they could begin to get to know one another more informally.

- Topic 3 Cultural Values: Guidelines for Behavior 
Discussion Topic: This week examines the concept of high and low-context cultures. What problems can you anticipate when you are communicating with someone who holds a different context orientation and how do you overcome this challenge (use your chapter reading and lecture to assist with your answer)?

The aim of this topic was to discuss cultural values and guidelines for behavior.

We also tried to explain different ways culture is acquired and outlined factors that contribute to how people from a culture see the world and specifically through religion, family and history.

During the third week, it is important to continue to build on prior dialogue related to your selected topic.

- Topic 4 Cultural Influences on Communication Contexts: Responding to the Setting

Discussion Topic: This week the students will work with their partner to put together a PowerPoint presentation summarizing all they have learned from each other during these past 4 weeks. They were required to narrate the PowerPoint presentation.

This section focuses on how people from different cultures interact in the context of communication. Most of the time there may be a misunderstanding because communication partners may not be operating under the same sets of rules (i.e. direct versus indirect communication, or formal versus informal communication) and it is important for students to gain this understanding when relating to others from another country since this is a common mistake made.

The course continued for two more weeks independently where students worked with their partners and collaborated by preparing a PowerPoint presentation about their cultural learnings. They then shared this with the class and a final discussion took place.

\section{Challenges related to culture}

One key challenge/opportunity to teaching any course where people are from different countries is the impact of culture. Culture needs to be considered when working collaboratively because much of what we've learned, perceive, and believe is learned within the social context of culture (Nelson \& Quick, 2015). In this case it was no different. The composition of the United States students was primarily self-identified as American, having been born and raised in the U.S. even though some of their ancestors came from different countries; two students self-identified as Peruvian and Polish and were born in these countries and partially raised there. In the case of the Mexican students most where self-identified as born and raised in Mexico and one visiting student from Colombia. The size of both classes was approximately twenty-five students, between the ages of 20 and 45 years of age completing their undergraduate/graduate degrees in Business Administration. The challenges related to culture can best be analyzed using Geert Hofstede's cultural dimensions since his research "found that national culture explains more differences in work-related attitudes than does age, gender, profession or position in the organization" (Nelson \& Quick, 2015, p. 18). The Hofstede's dimensions most observed by faculty between the United States and Mexico are:

Individualism versus Collectivism, where individualism is "defined as loosely knit social framework in which people are supposed to take care of themselves and of their immediate families only," (Hofstede, 1980 , p. 45) whereas collectivism is "characterized by a tight social framework in which people distinguish between ingroups and outgroups, they expect their ingroup to look after them, and in exchange for that they feel they owe absolute loyalty" (Hofstede, 1980, p. 45). This was manifested in some of the responses from the students within the discussion board:

\section{As one Mexican student wrote:}

“...Talking more about my family, I live with my close family, my mom, my dad and my little brother. We are extremely close. We used to spend our weekends together, listen to each other, see movies, exercise or play some table games. Since I began college, the time we spend is less than it used to be, even then we try to remain connected" (Universidad La Salle Mexico, 2014).

Or "...Culture as a topic has always interested me because there are so many differences and similarities from country to country and within each country. In contrast to other places, Mexico isn't as diverse in its population. We do share many values and beliefs because our main foundation is the family. Families tend to be large, loud and very close. For instance, it is very normal for children to live with their parents until they get married no matter how old they may be. It is also common to have the grandparents or even aunts, uncles, cousins, etc. living in the same house. In my case, I live with my immediate family, but I see members of my extended family every other day and we are in constant communication--love, support, and laughter are definitely the strength that keeps us together" (Universidad La Salle Mexico, 2014).

Note: The scheme of family in Mexico is undergoing a transformation, which is mainly due to socioeconomic reasons. This transformation is best observed in young Mexican nationals that are attending college. At La Salle University, for example, the majority of the students come from the Mexican middle class whose characteristics are: the bond of parents is marriage, that is to say it is a formal link. Also, the parents still have the role of provider. These features are evidence of a stable economic situation, which allows these students to develop a comfortable life without worries. However we can see a variety of statements, because while this is generally true not every student meets the above characteristics

Or "... a sense of helping a person in need is really instilled in the Mexican community just like in many other places whenever help is needed" (Universidad La Salle Mexico, 2014). 
In the case of the American student, the following statements were made

“...I was born Catholic but I am now a Born-again Christian, I do not really practice certain customs besides the fact I read my bible and try to stay on a right path. I live in a 2 story house and live with 8 people in my house and also have 2 dogs as well. In my family we have 4 boys, my mother and my step-father and also my older brother's fiancé and her daughter. Family is very important to me and means everything to me because in my family we are very close and can rely on each other for anything. We always support each other and could not be any closer" (Universidad La Salle Mexico, 2014).

Or "... I live with all my family. Family means a whole lot to me. It >s were I get my morals and ethics and values. Whenever I need advice, help, or just someone to talk to I never hesitate to contact them. They help me through my tough times" (Universidad La Salle Mexico, 2014).

The second dimension evident in the discourse between students is Power Distance. Power Distance as defined by Hostede is, "the extent to which a society accepts the fact that power in institutions and organizations is distributed unequally" (Hofstede, 1980, p. 45). The assumptions were that there would be some clear distinctions between the two cultures however there seemed to be more similarities in the perception of roles. The following are excerpts of those discussions that help to explain some of the institutionalized roles.

"...The roles of men and women in our country have been defined by the "Mexican macho": men work in order to provide for the family and women have to stay home to take care of their husbands, children, housework, etc. Luckily, this notion has been evolving for some years now and women are having more and more opportunities equal to those of men at a professional level. It's becoming more common to have two working parents in the family unit and the men helping somehow at home. When it comes to taking care of the children, babysitters per se aren't common at all! It's usually the grandparents, maids (because those are common, live-in or part-time, but not nearly as costly as in other countries) or the oldest child who usually take care of the children--not someone hired specifically for that" (Universidad La Salle Mexico, 2014).

Whereas an American student made the following statement "...In Asian cultures, the elderly are looked at as wise and humble human beings, whereas the United States do not seem to value our elders as the same. Also, other countries make females the lowest of people, meaning they don't have in impact or a say in how anything runs, whereas in America women can be just as powerful as men" (Universidad La Salle Mexico, 2014).

And "The topic of gender roles in different cultures is amazing. I consider my wife as an equal partner in life in terms of working together for the common goal in life" (Universidad La Salle Mexico, 2014).

It appears that within the City of Mexico and U.S. that as the roles of families is changing due to financial burdens of raising families and therefore the experiences of these two groups seems to be growing more similar.
Age of students also had an impact on perceptions, students' age range from 20 to 45 years, with the majority of both student groups (U.S and Mexico) being of traditional college age and a few U.S. students who were 30-45 years of age. For those students paired with the older colleagues it made the project a bit difficult at first, for example students of the University of La Salle (more traditional college age) were not used to interacting with students outside their age group. However, the life experience these older students bring to the classroom is of great value in adding to the diversity of learning gained in this course.

Time Orientation in reference to Time Orientation Hofstede distinguished between short term versus long term orientation. Where the short term orientation "refers to past-and-present oriented values such as respect for tradition and fulfilling social obligations," whereas long-term orientation refers to "future oriented values such as persistence and thrift," (Hostede, 1980, p.46), in the case of both Mexico City and the U.S. students in this course, it appears that both are longterm oriented and this was demonstrated in the following statements:

"In my country Colombia the culture is formed by the family, the customs, for example. The 7 th of December is a very important date for the union of the family because we celebrate the "Día de las velitas" ("Day of the Candles"), is a very typical celebration, we celebrate the Immaculate Conception of the Virgin Mary, we turn on candles with the all family together" (Universidad La Salle Mexico, 2014).

“...Like in population, diversity in religion isn't too big. Mexico does have big Jewish, Christian, Mormon, Jehova Witness communities, but the religion that definitely prevails is Catholicism. Worshipping Jesus, Virgin Mary, and saints is part of the culture. In fact, every December 12th., Virgin Mary's Day, between 1 and 3 million people from different parts of the country visit the Basilica de Guadalupe here in Mexico City--some come by bus, others by bicycles, others walking and some even kneeling for kilometers and kilometers--to see an image/painting of Mary to thank her for all the blessings she's given them; and then, they leave right away. That's also why, the most common names for girls are Maria or Guadalupe and for boys Jose or Jesus. Religion in Mexico is a defining aspect of our culture for sure" (Universidad La Salle Mexico, 2014).

And also "We also are patriots so that's what we love to celebrate our Independence Day, although more than the $85 \%$ of population live in big cities as Mexico or Monterrey and they have adapted to the changes of modernity, we keep traditions from our ancients the rest of the year like November 2nd when we commemorate our dead loved ones making for them an "ofrenda"(gift) with especial flowers that are cultivated only for that date and food that they liked. For Catholics one of the most important dates is December 12th the day of la Virgen de Guadalupe, or posadas which are celebrated from December 16th to 24th when it's Christmas, there are many religion traditions which are celebrated in all states but maybe of different way and also each one has their own, all the saints have their day too, and it's pretty common celebrate if your name is the same as one of them" (Universidad La Salle Mexico, 2014). 
From the U.S. students' perspective they reflected on work ethic in terms of passed down values:

"My schooling and my work ethic have always been stressed in my family. From the time I was a little girl I was always expected to do my best in school. My grades expressed my hard work. All throughout middle and high school I had straight A's. I also started working when I was 17 . I've worked $30-40$ hours every week since I was 17 along with full time school" (Universidad La Salle Mexico, 2014).

And "In the United States people tend to try to be successful and take pride in moving up the social ladder. Individual accomplishment really means something. Owning a big house and nice cars is a goal that many have. Americans like to be in control of what's around them" (Universidad La Salle Mexico, 2014).

In most cases in order to gain this first-hand experience, one must travel to a given country and immerse oneself in the culture. What is evident here is that through the use and incorporation of this blended learning instructional environment, students gained a better appreciation of some of the similarities and differences between Mexico City and the U.S. college students. Students expressed that they gained a better appreciation of the other's culture and this diminished misperceptions about each other, which they had been exposed to primarily through television.

This was expressed in the following statements:

"We had a great and lengthy discussion about food. Student X talked about how food in Mexico tends to be spicy. This is not the case in Colombia. I talked at length about how food in the US changes from region to region."

Yet another student stated, "Student Y and I have been communicating back and forth over the past week about what's going on in our lives and some of our cultures values and differences. One tradition that I still find interesting is the day of the dead that falls on November 2 nd where they allow their dead loved ones into their house to visit. At this time they put out what is called an ofrenda. An ofrenda is an altar that consists of things that the dead relatives enjoyed during life. They set up pictures, favorite foods, clothing, toys, incense, candles and sugar skulls. One thing that confused me at first was why put out food? Do they believe the dead eat it, like children believe Santa eats the cookies? But come to find out the aroma of the favorite foods is what the spirits enjoy.

Both Student $\mathrm{Y}$ and I agree that family is the most important thing in life. I think one difference I notice between cultures is that in the U.S. we have become more of a grab and go culture. Fast food has become more of the way of life instead of sitting down and enjoying family with large family dinners. Sure we get together on a few holidays, but the daily and weekly routine of family time I feel is being lost. Student Y said her family frequently has family dinners and have many passed down family recipes that are used on special occasions."

\section{Challenges related to LMS}

Although both institutions use Moodle LMS, it presented unique challenges. In the case of the U.S. institution, Moodle had only been adopted within the beginning of the academic semester in which this course took place. Both the students and faculty were unfamiliar with Moodle, and found the system cumbersome and not intuitive. Difficulties in uploading files to be shared among students was a key challenge and in many instances students had to rely on emailing files because of the limitation on file size available through Moodle. This limited our ability to collaborate effectively.

For La Salle University, there was no prior training in the use of the platform. This made it very challenging for students who opted for alternative media, such as Facebook, to complete the activities of the project.

For future collaborations these challenges should be addressed more thoroughly before beginning the course. It may make more sense to use a tool like Facebook, via a closed group setting, to facilitate the course.

\section{Institutional Support}

Essential to the success of any new innovative methods of instruction is the institutional support provided by the university there and here, too; there were some key differences. The U.S. institution was very supportive, providing technical support in the course facilitation, funding for travel, and maintaining open channels of communication; including setting up conference calls between both institutions' faculty, program directors and technical support.

Within the Mexican university, while there was verbal support for this collaboration, there was very little support in funding and communication. This exchange experience confirms the need and importance of continued institutional support at the various stages of implementation of cooperative agreements and to a framework which incorporates guidelines for academic credit for the work completed by students to reward them for their participation, which was the case in one of the two institutions.

\section{Opportunities}

Despite some of the technological and institutional support challenges, it is agreed by both instructors that given the opportunity to participate in this form of instruction, we would undertake this opportunity. The collegial experience and friendship developed enabled us to overcome the challenges. However, the greatest benefit to this form of instruction was derived by the students who came away with a very unique experience. It broadened the perspective of students. As more and more countries sign trade agreements with each other, it becomes an urgent need in the globalized world to go further to know, to understand, and to even appreciate in other's realities. 
Provided both instructors can engage and form a collaborative team environment with each other, this type of instruction can be applied in all fields and at all levels of undergraduate and graduate education provided there is institutional support, a technology platform that facilitates oral and written communication, similar curriculums with course credit, and the desire to challenge and engage students' perceptions and views of the world around them.

\section{Recommendations for future Collaborative Online Instruction and Conclusion}

Going forward what we would do differently is ensure all students have had training on the selected LMS of instruction, ensure institutional support and buy-in has been secured at all levels of the institution, especially from upper administration. Secondly, and equally as important is buy-in from students. This course should be a voluntary course for credit, similar to a study-abroad program so that both groups of students have a tangible gain to show on their transcript.

It requires the department in charge of the project, which in the case of La Salle University's School of Business, should be involved in a comprehensive manner. Administrators, teachers and students should have certainty about the extent of their participation: roles, achievements and encouragement, as evidence of an organized and effective leadership.

Also, the university should ensure there is adequate space for interactions during the project, with the understanding that the exchange between partners is primarily virtual. There must be an appropriate platform and training in order to facilitate good performance. We should consider strategies to achieve these.

Despite these challenges, the benefits achieved far outweighed them. Students, through this innovative pedagogy, had the opportunity to engage with colleagues located in a different country and learn to appreciate their similarities and differences. While they may never meet each other personally they came away from this course with a far better understanding of the global challenges they will face when they enter the workforce. Today, as educators, we are keenly aware that the student of today wants "choices" (Burian, Muhammad, Burin \& Maffei, 2012) in terms of what they are being exposed too and the tools we use to teach them. Through this virtual collaboration students learned about the differences between cultures through actual exposure to another culture without having to leave home.

\section{Acknowledgements}

The authors would like to acknowledge the institutional support of The State University of New York (SUNY) Cobleskill, Cobleskill New York, La Universidad de La Salle, Mexico City, Mexico and SUNY's Collaborative Online Institutional Learning Center who provided the faculty the opportunity to participate in this program.

\section{References}

Allen I. E., Garrett, R., \& Seaman, J. (2007). Blending in the extent and promise of blended education in the United States. Sloan Consortium, 1-35. Retrieved on April, 10,2015 http://www.sloanconsortium. org/sites/default/files/pages/Blending_In.pdf 2

Burian, P. E., Muhammad, B., Burian, P. S., \& “Skip” Maffei, F. R. (2012). The manifest destiny of education: Past, present and beyond the boundaries of tradition. Contemporary Issues in Education Research (Online), 5(4), 301. Retrieved from http://search.proquest. com/docview/1418450299? accountid=28700

Folkers, D. A. (2005). Competing in the marketspace: Incorporating online education into higher education - an organizational perspective. Information Resources Management Journal, 18(1), 61-77. Retrieved from http://search.proquest.com/docview/215883641?accountid $=28700$

Hofstede, G. (1980) 'Motivation, Leadership, and Organization: do American theories apply abroad?' Organizational Dynamics 9(1): $42-63$.

Nelson, D. L., \& Quick, J. C. (2015). Orgb: Organizational behavior ( $4^{\text {th }}$ ed.). Stamford, CT: Cengage Learning.

Samovar, L. A., Porter, R. E., McDaniel, E. R., \& Roy, C. S. (2013). Communication between cultures. Boston, MA: Cengage Learning.

Universidad La Salle Mexico. (2014, September 16). Universidad La Salle A.C.: Entrar al sitio. Retrieved from http://ulsa.we-know.net/licenciatura/mod/forum/discuss.php?d=2094 